\title{
Evaluation of explosion loading effects on concrete infrastructures using ABAQUS software
}

\author{
Abolfazl Rahimi \\ Department of Civil Engineering, Jahrom Branch, Islamic Azad University, Jahrom, Iran \\ E-mail: Abolfazl_rahimi@jia.ac.ir
}

Copyright $\odot 2015$ Abolfazl Rahimi. This is an open access article distributed under the Creative Commons Attribution License, which permits unrestricted use, distribution, and reproduction in any medium, provided the original work is properly cited.

\begin{abstract}
One of the most important facilities of a country is Fluid Reservoirs which should be secured against different damage of explosion. Reservoir structural failure after explosion not only could lead to economic losses, but also could cause water shortage and toxic leakage. In this paper a reservoir is modeled in ABAQUS software. The results for displacements and deformations, energy dissipation of various forms and principal stresses are illustrated.
\end{abstract}

Keywords: Reservoir Behavior; Blast Loading; Dynamic Analysis.

\section{Introduction}

Explosion protection is used to protect all sorts of buildings and civil engineering infrastructure against internal and external explosions or deflagrations. It was widely believed [1] until recently that a building subject to an explosive attack had a chance to remain standing only if it possessed some extraordinary resistive capacity. This belief rested on the assumption that the specific impulse or the time integral of pressure, which is a dominant characteristic of the blast load, is fully beyond our control.

It is important to design safe structure for natural disasters such as earthquake and explosions. Such structure not only is used for conventional loads, but also for reinforcing against explosion. One of the most important facilities is fluid reservoirs which should be secured against explosion. Reservoir structural failure after explosion not only could lead to economic losses, but also could cause water shortage and toxic leakage. Metal reservoirs have been used in Iran and other country commonly. Thus, developments of concrete structures make the study of these structures inevitable. Underground reservoirs are mainly used for petroleum products and water storage. First let us present generalities about reinforced concrete reservoirs then explain scientific principles, concept and equations and modeling. The ending is conclusion and recommendation.

\section{Literature review}

The topic of the research is widely investigated in passing years, for some instances due to blast loading, some recent articles are summarized.

Clubley presented a paper titled long duration blast loading of cylindrical shell structures with variable fill level. This paper investigates the effect of long-duration blast loads on the structural response of aluminium cylindrical shell structures containing varying fluid levels. A detailed non-linear numerical model comprising remapped Lagrangian analysis examines localised plate buckling and deformation. This paper highlights the key influence on blast response due to varying internal fluid levels and the relative importance pertaining to a conservative design solution for varying operational states. Numerical modelling in this paper demonstrates the robust accuracy achievable for a remapped Lagrangian solution. The routine analytical assumption of uniform drag forces acting on the structural body was shown to be both misleading and inaccurate by comparison. This research will be of direct interest to both practitioners and researchers considering high power explosive blasts from sources such as hydrocarbon vapour cloud ignition [1]. 
Henchie in 2014 presented the study on the response of circular plates to repeated uniform blast loads: An experimental and numerical study. This paper presents the results of an experimental and numerical investigation into the response of circular Domex-700 MC steel plates to repeated uniform blast loads. The results also show a decrease in the incremental mid-point deflection and an increase in the Vickers hardness of the plate at the boundary and central region with increasing number of witnessed blast loads. Numerical simulations are carried out to gain further insight into the deformation of plates subjected to repeated blast loading using ABAQUS/Explicit v6.10.1 in conjunction with the inbuilt blast function code, ConWep. A scaling factor is adopted to model the amplified blast wave resulting from the detonation of cylindrical charges at one end of a cylindrical tube. Very good correlation is obtained with regards to midpoint deflection and deformation profiles. The plastic strain obtained numerically shows good qualitative correlation with the experimental Vickers hardness tests [2].

Chen ET. Al. studied on Numerical analysis of prestressed reinforced concrete beam subjected to blast loading. They mentioned that prestressing technique has been widely used in civilian and military constructions. The prestressed reinforced concrete (RC) structural components such as beams and columns usually outperform the non-prestressed RC components because prestressing not only increases the structural stiffness and load carrying capacity, but also has higher crack resistance than non-prestressed component. The effectiveness of prestressing on blast-resistant capacity of $\mathrm{RC}$ beam is demonstrated through comparing the results with the bench marking non-prestressed RC beam under the same blast loading [3].

\section{Research method}

Numerical solution of the explosion has been considered in recent decade and lead to develop of software stimulation. According to high construction costs and limitation in solving theoretical problems to test explosion, the importance of numerical stimulation is highlighted more than before. Software could solve dynamic problem in solid, liquid and gas condition by considering linear and non-linear behavior of materials including plasticity, hardening, strain softening and breakdown. One of this software is ABAQUS. In this season it is assumed that surface explosion had occurred in specific power and distance considering soil, structure and fluid specification. Explosion waves are transmitted through the soil reservoir. In this problem the effects of soil, fluid and structure has been considered so, we explain different method of stimulation in ABAQUS. Briefly then, model reinforced concrete reservoir, fluid and soil condition in different modeling method and the models is being created under time bombing.

\section{Modeling procedure}

ABAQUS is a collection of engineering stimulation software which is designed based on finite element method and could solve wide range of linear to non-linear analysis. This software has many features for stimulating linear and nonlinear application. Some problem that include of several different component and materials could be stimulated by geometric defining of each component and assigning the constituent materials then defining cement conductor between them. Other features of this software are stimulating and analyzing explosion phenomena, its response and wave propagation. The figure presented shows tension and strain on soft and hard soil.

Table 1: Plastic Characteristics

\begin{tabular}{ll}
\hline Yield Stress $(\mathrm{Pa})$ & Plastic Strain \\
\hline $300 \times 10^{6}$ & 0 \\
$350 \times 10^{6}$ & 0.025 \\
$375 \times 10^{6}$ & 0.1 \\
$394 \times 10^{6}$ & 0.2 \\
$400 \times 10^{6}$ & 0.35 \\
\hline
\end{tabular}

Table 2: Loading History

\begin{tabular}{ll}
\hline Time & Amplitude \\
\hline 0 & 0 \\
0.001 & 700000 \\
0.01 & 700000 \\
0.02 & 0 \\
0.05 & 0 \\
\hline
\end{tabular}




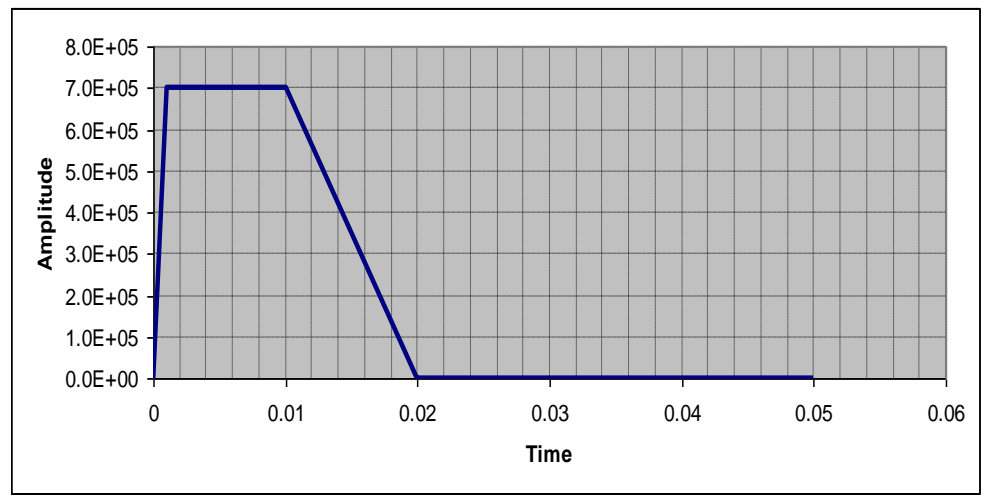

Fig. 1: Blast Loading History

\section{Results}

\subsection{Comparison of dissipated energy}

By analyzing the model, the von mises stress contour is plotted as below.

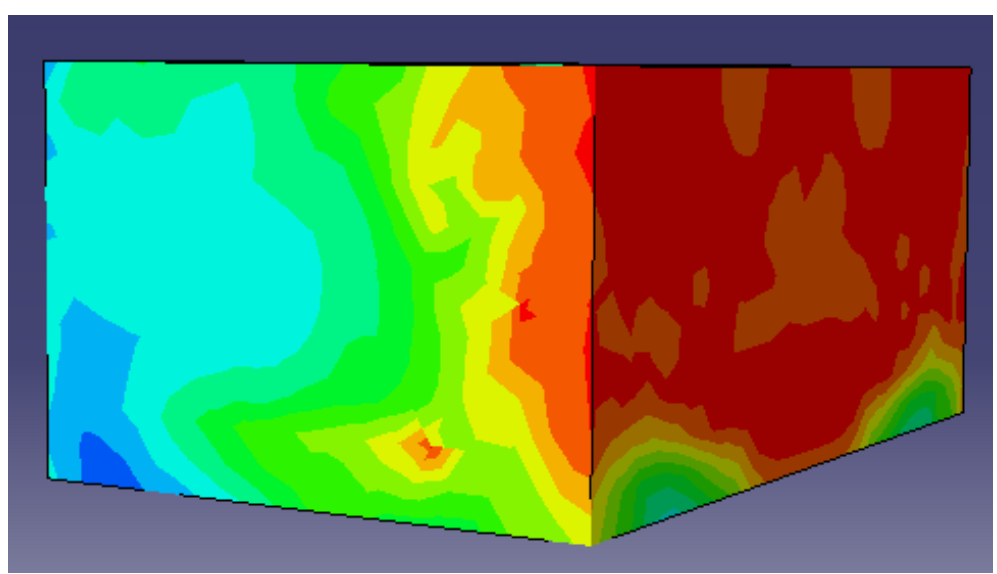

Fig. 2: Von Mises Stress Contour on Initial Condition of Reservoir

Thus, it is needed to demonstrate the energy dissipation (rise and attenuation) during explosion near the structure. To make a better understanding of the behaviour for structure, the below items are illustrated:

- $\quad$ Artificial Strain Energy

- Internal Energy

- $\quad$ Kinematic Energy

- $\quad$ Strain Energy

- $\quad$ Total Energy

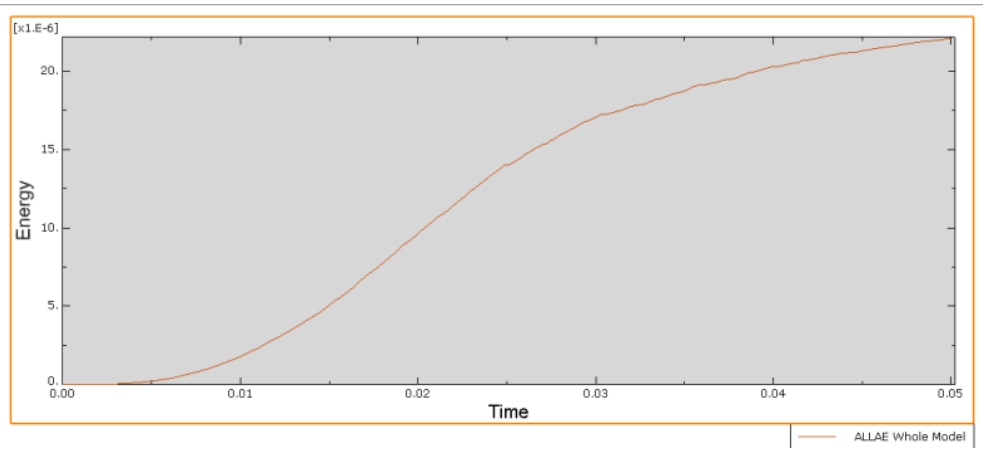

Fig. 3: Artificial Strain Energy in Whole Model

Based on the artificial strain energy in the model of reservoir in ABAQUS, the plastic strain are clearly visible at intersections of walls. 


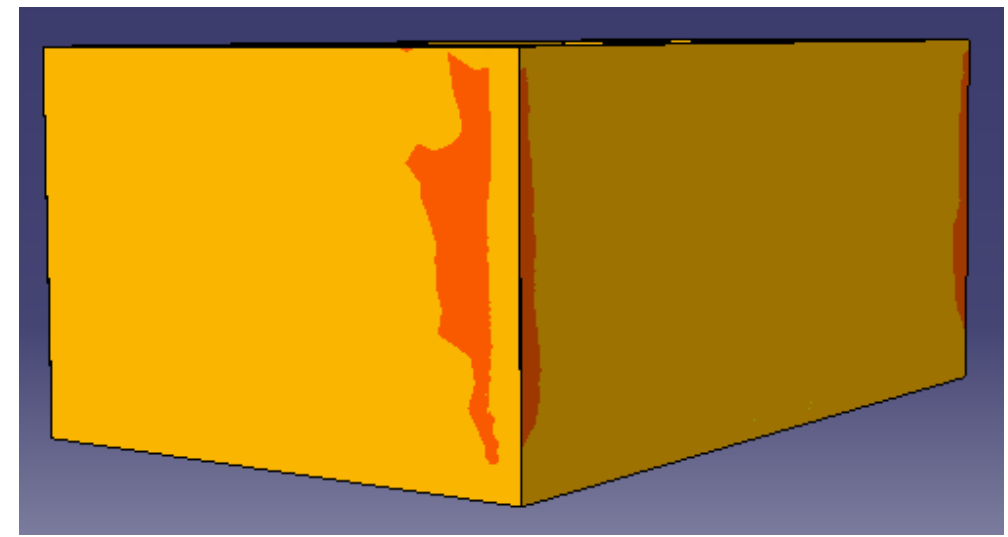

Fig. 4: Plastic Strain Resulting From Explosion

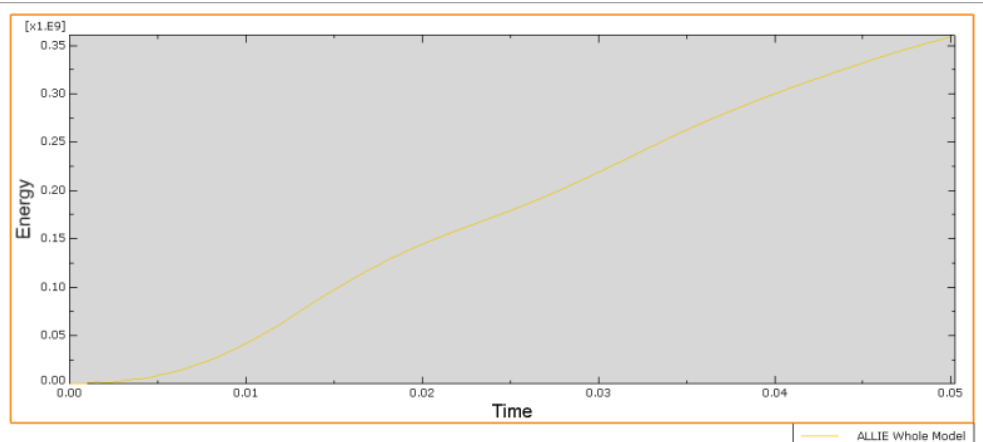

Fig. 5: Internal Energy in Whole Model

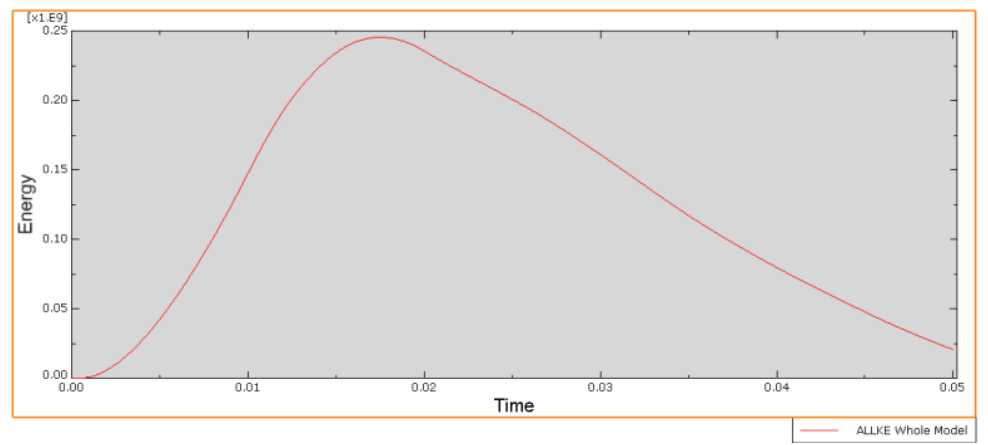

Fig. 6: Kinematic Energy in Whole Model.

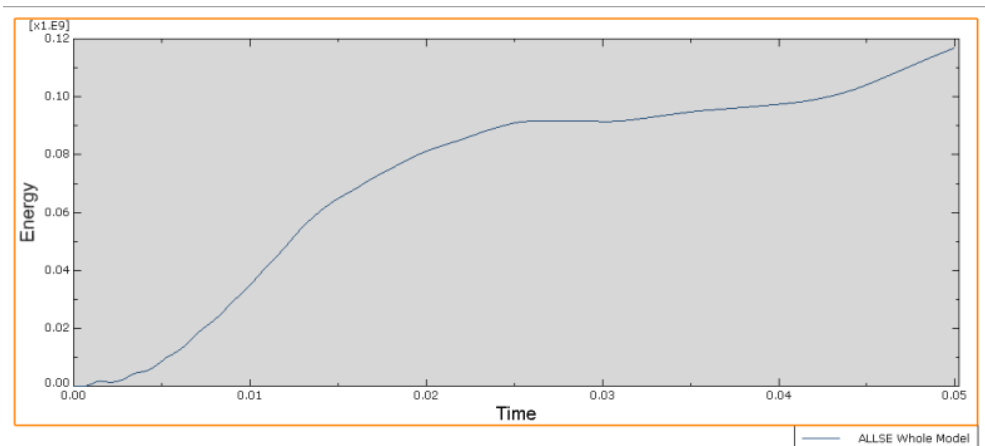

Fig. 7: Strain Energy in Whole Model. 


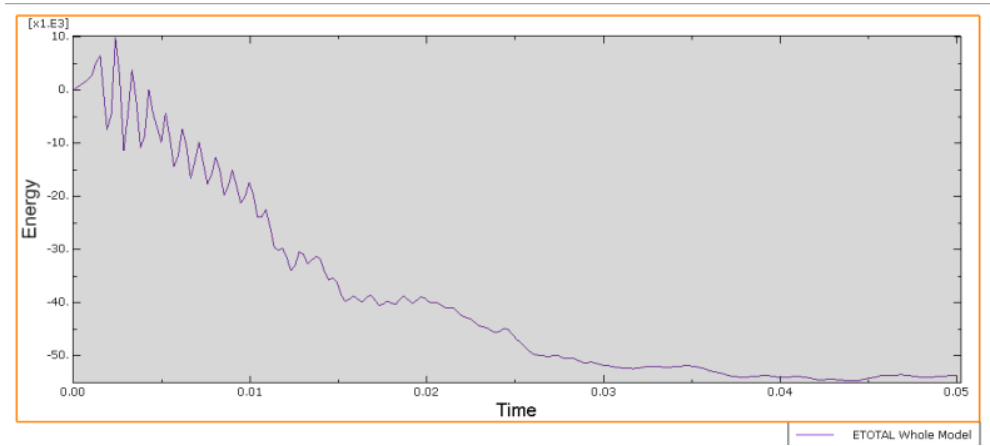

Fig. 8: Total Energy in Whole Model

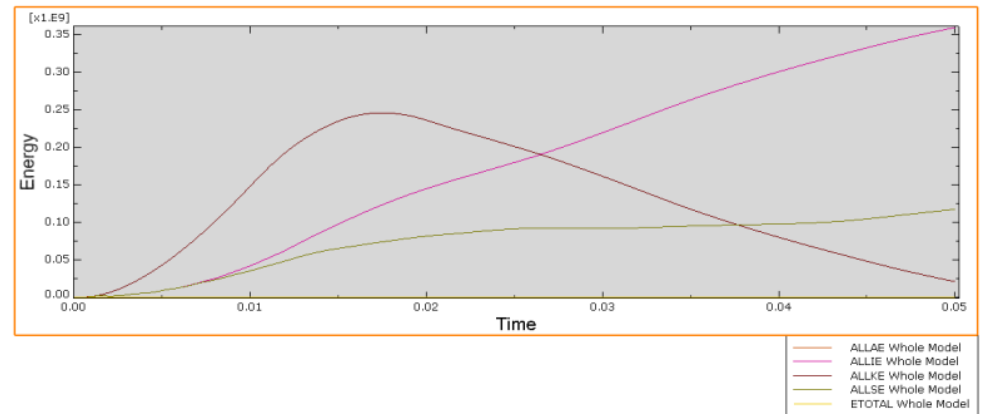

Fig. 9: Comparison of Various Energy Details in Whole Model

\subsection{Comparison of global displacement}

In the below figures, the global displacement for $\mathrm{x}, \mathrm{y}$ and $\mathrm{z}$ direction are plotted separately.

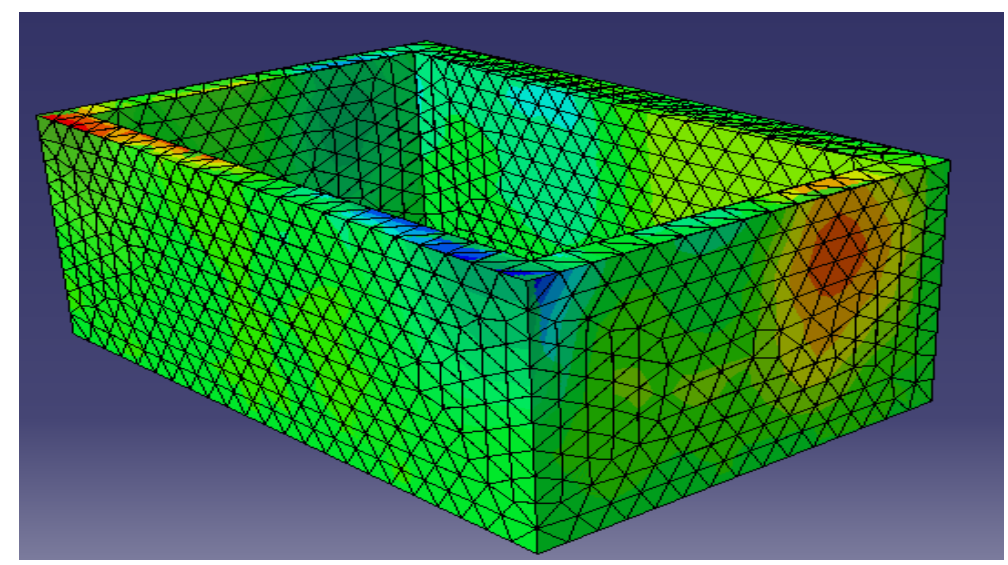

Fig. 10: Displacement in X Direction

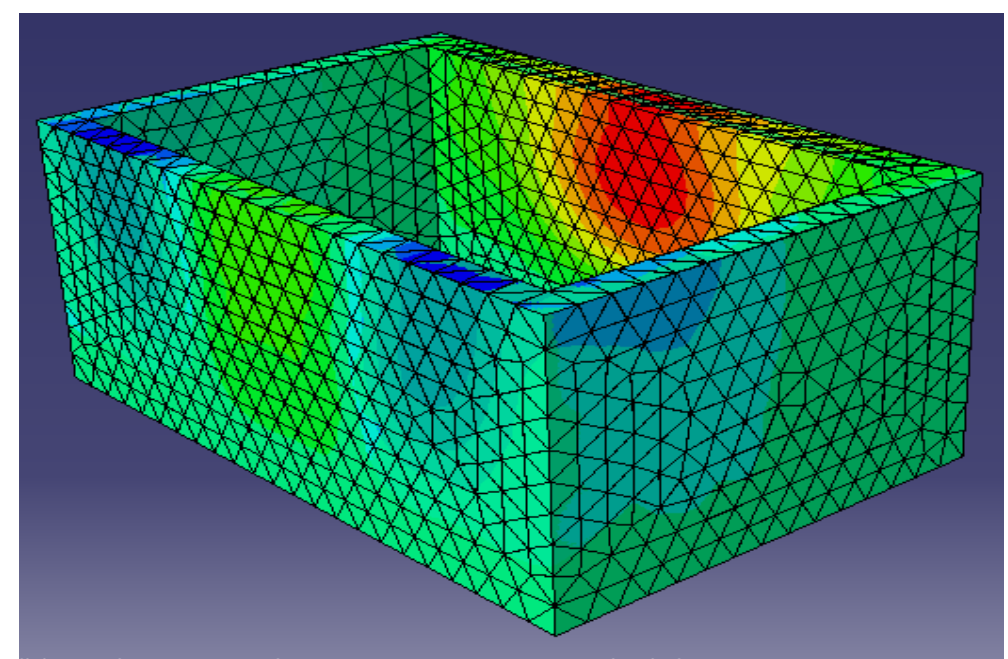

Fig. 11: Displacement in Y Direction 


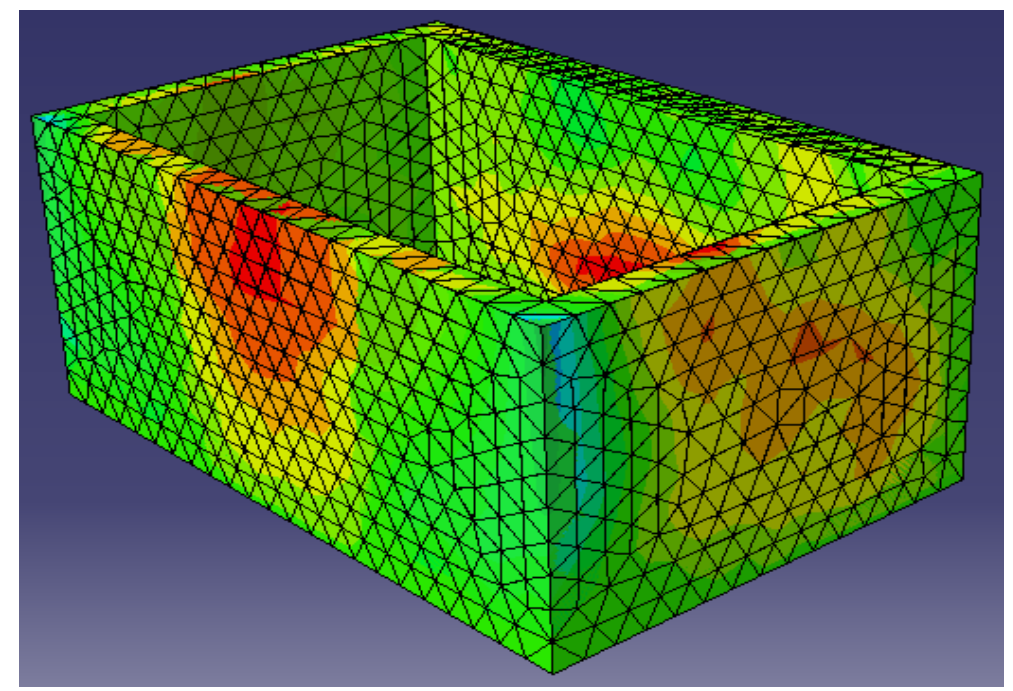

Fig. 12: Displacement in Z Direction

\subsection{Comparison of stress condition in various soils}

When a reservoir is constructed in hard soil and time bomb is occurred in the left of the wall, maximum tension occurred in top corner and minimum tension is been seen in the middle. In right the result is the same. In the ceiling, maximum tension in been seen in near right and left and minimum tension is been seen in the middle. Maximum tension has been seen in top and minimum in the middle under earthquake load. Maximum strain occurred near left and right and minimum strain in right and left and middle of ceiling (figure2).

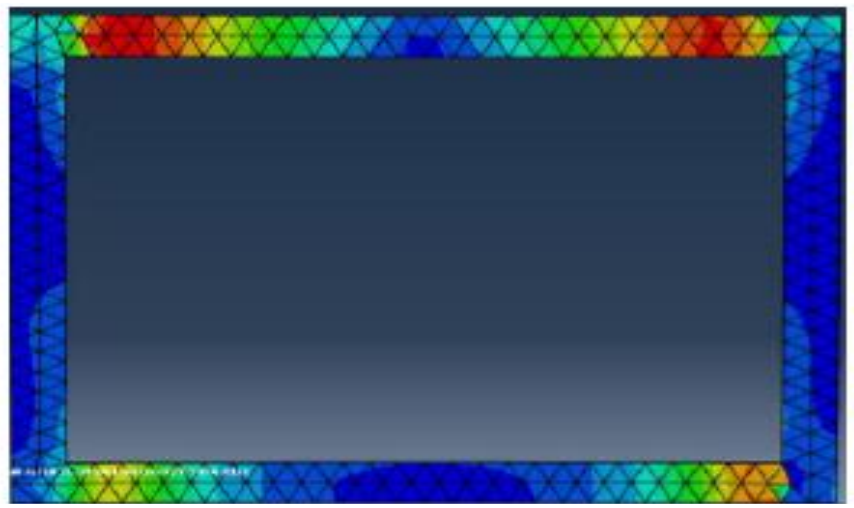

Fig. 13: Stress Contour in Hard Soil

Maximum tension occurred in top corner of left wall and minimum tension occurred in bottom of the right wall and minimum tension occurred in the middle of left wall and minimum tension occurred in middle and top of the right wall. In ceiling, maximum tension is been seen in right and left, minimum tension in been seen in middle. Maximum tension occurred in left and right hand of ceiling and we have minimum tension in middle under earthquake load. Maximum tension is been seen in top left and bottom left of the walls (figure3).

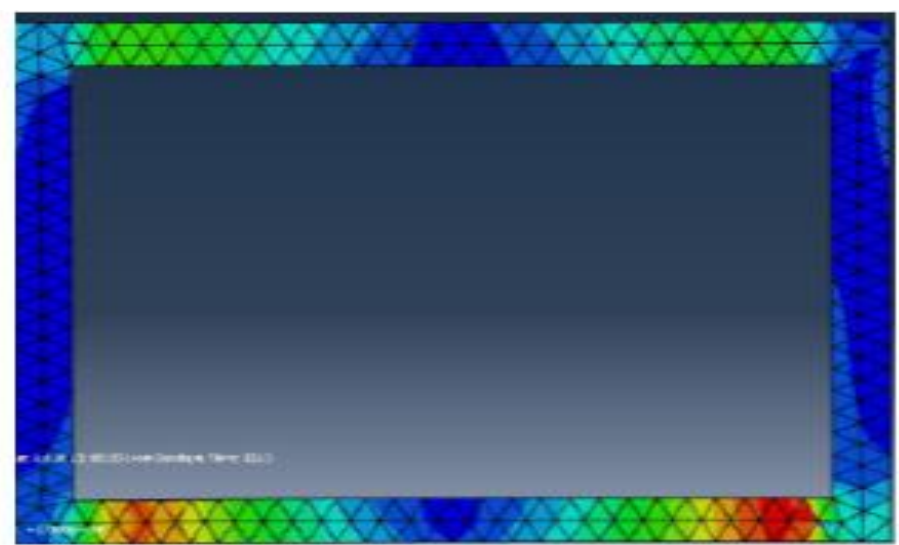

Fig. 14: Stress Contour in Soft Soil 
Maximum plastic strain occurred in left and right of ceiling and minimum plastic strain occurred in left, right and middle of ceiling. In middle of ceiling we see maximum deformation and minimum deformation occurred in corners. The wall deformation is occurred the same.

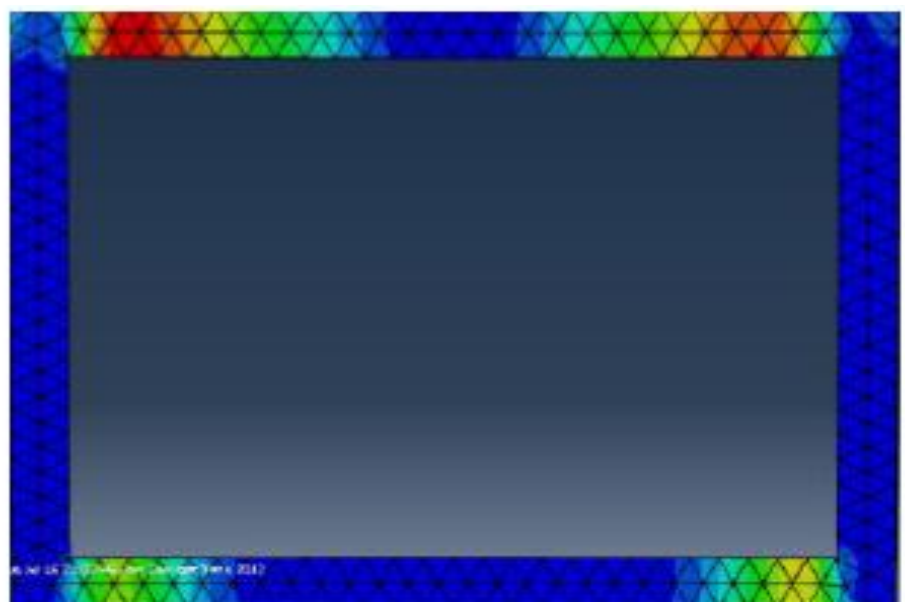

Fig. 15: Plastic Strain Contour in Hard Soil

Minimum strain occurred in left, right and middle of ceiling. Maximum stain is been seen in left and right.

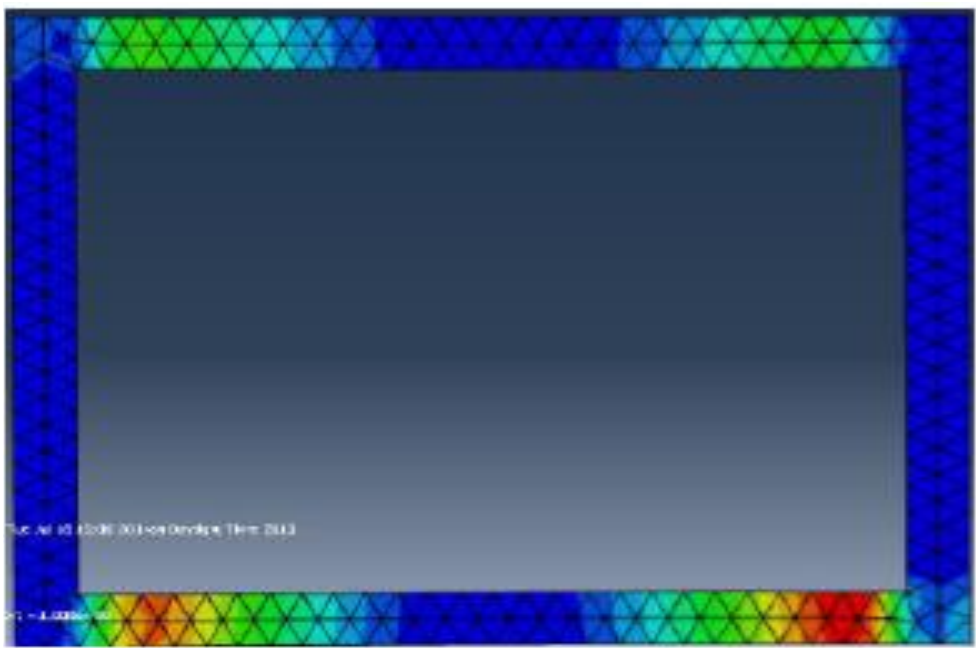

Fig. 16: Plastic Contour in Soft Soil

Wall deformation in wall and ceiling is partial in soft and hard soil.

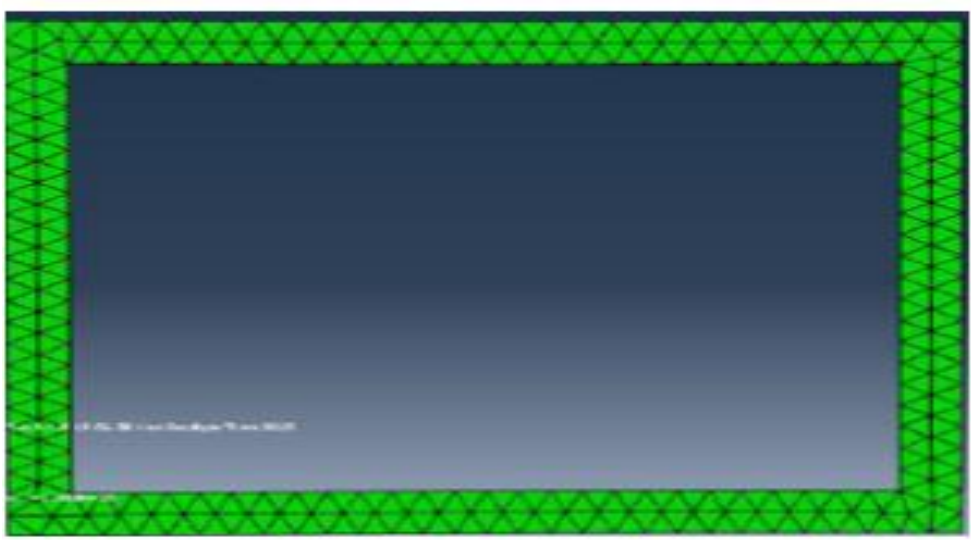

Fig. 17: Deformation Contour in Soft and Hard Soil 


\section{Conclusion}

The result demonstrated that:

- Maximum strain of plastic occurred in wall and ceiling corners and minimum strain of plastic occurred in middle on explosion.

- $\quad$ Maximum deformation occurred in middle of wall and ceiling and minimum deformation occurred in corners on explosion.

- Maximum plastic strain occurred in right and left hand of ceiling and minimum plastic strain occurred in right, left and middle of ceiling.

Wall deformation in wall and ceiling is partial in soft and hard soil.

\section{References}

[1] Simon K. Clubley, Long duration blast loading of cylindrical shell structures with variable fill level, Thin-Walled Structures, Volume 85, December 2014, Pages 234-249.

[2] T.F. Henchie, S. Chung Kim Yuen, The response of circular plates to repeated uniform blast loads: An experimental and numerical study, International Journal of Impact Engineering, Volume 74, December 2014, Pages 36-45 http://dx.doi.org/10.1016/j.ijimpeng.2014.02.021.

[3] Wensu Chen, Hong Hao, Shuyang Chen, Numerical analysis of prestressed reinforced concrete beam subjected to blast loading, Materials \& Design, Volume 65, January 2015, Pages 662-674 http://dx.doi.org/10.1016/j.matdes.2014.09.033. 